\title{
Chapter 7 \\ How Rating Systems Support Regenerative Change in the Built Environment
}

\author{
Melinda Orova and András Reith
}

\begin{abstract}
Urban development principles have evolved from sustainability, where the focus was on limiting the negative impact of urban environment, to restorative and regenerative sustainability, where positive impact is needed on global social and ecological systems. This recent paradigm shift requires the development of new tools for practitioners, like design methodologies, new technologies, and assessment methods.

To measure the impact of sustainability on the built environment, several building-scale assessment tools exist. The question is how these widespread rating systems support restorative change in the built environment.

The main question of the research is answered in three methodological steps. First, the goals of restorative sustainability are summarized from the available extensive literature, including the topics of Place, Energy, Water, Well-being, Carbon, Resources, Equity, Education, and Economics. Then different rating tools (Living Building Challenge, WELL, LEED, BREEAM, DGNB) are analysed how the considered issues and indicators in these rating tools are connected to restorative goals. Then these indicators are assessed how they serve that goal.

The result of this study shows the main strengths and gaps in current wide-spread international rating tools regarding their support of restorative sustainability.
\end{abstract}

Keywords Sustainability rating tools · Indicators $\cdot$ LEED $\cdot$ WELL $\cdot$ Living building challenge

M. Orova $(\triangle) \cdot$ A. Reith

ABUD Mérnökiroda Kft., Budapest, Hungary

e-mail: orova.melinda@abud.hu; reith.andras@abud.hu 


\subsection{Introduction}

Regenerative and restorative architecture are emerging approaches for addressing the shortcomings of the current sustainability paradigm, as numerous segments of society have begun to accept that merely limiting the negative effects of human interventions into nature is no longer sufficient (Sonetti, Brown, \& Naboni, 2019).

Most of the current literature (Attia, 2016; Bayulken \& Huisingh, 2015; Du Plessis \& Brandon, 2015; Hes \& Du Plessis, 2015) define regenerative sustainability alongside two key points (Akturk, 2016): the principle of not conserving the status quo but to effect net positive impact on the built environment and the concept of integrating positive human processes and creating natural environment that can continue regenerating itself.

To support this change toward a regenerative worldview, experts on the field are developing new design and construction support tools as well as new technological solutions for the implementation of regenerative principles. There is also a need to measure the regenerative performance of building projects so as to be able to compare them to the industry state of the art and to communicate the regenerative sustainability objectives effectively.

For sustainability projects, extensive literature covers these performance metrics grouped into sustainability indicator sets (Haapio \& Viitaniemi, 2008; Illankoon et al., 2017; Lazar \& Chithra, 2020). The sustainability indicator sets that are used as rating tools on the construction market are to be considered as a benchmark for quality.

Regarding regenerative architecture, limited literature exists on dedicated indicator sets in this field. For example, the Living Building Challenge (ILFI, 2019) assessment is promoted as a system providing a comprehensive set of regenerative performance metrics. Other design-support tools have also been developed that reference performance metrics, such as REGEN (Svec, Berkebile, \& Todd, 2012) and the LENSES (Living Environments in Natural, Social and Economic Systems) framework (Akturk, 2016). Also, Naboni et al. (Naboni et al., 2019) define urban scale regenerative criteria, including Key Performance Indicators (KPIs) for Urban Heat Island, outdoor comfort, energy efficiency, daylighting, and biophilia. The paper mainly focuses on KPIs that can be integrated into the digital design workflow. Some literature about regenerative indicator sets only covers some specific aspects of regenerative sustainability. COST-RESTORE (European Cooperation in Science \& Technology - Rethinking Sustainability Towards a Regenerative Economy) WG 4.1 a developed an indicator set for regenerative indoor environmental quality (EURESTORE, 2020) by relying on existing metrics, but redefining their thresholds to reflect the regenerative principles. Jiang et al. (2020) propose to include the restorative benefits of biophilia in assessment tools. McArthur and Powell (2020) investigated the inclusion of health and well-being criteria in eight key topics related to health and productivity in 11 international rating tools.

In literature, regenerative sustainability principle is considered as the next step in the evolution of sustainability (Bayulken \& Huisingh, 2015). Therefore, the 
question arises whether the development of sustainability indicator sets can also take the next step to cover the newly identified regenerative goals and raise their benchmarks towards requiring positive impact on humanity and the global environment. To get the answer for this question, it is at first necessary to investigate the status of currently used indicator sets. Therefore, the main objective of this research is to assess how existing indicator sets cover the main regenerative goals by cataloguing the existing indicator sets, then evaluating their utility towards regenerative sustainability.

In the following chapters, first, the most influential indicator sets to be investigated will be identified, then a quantitative and qualitative assessment will be described to define the existing gaps and to recommend the route to evolve towards reaching the regenerative goals.

\subsection{Rating Systems}

Based on the Brundtland report (UN 1987), the necessity of sustainable development was first recognized. Since then, several sustainability indicator sets were developed in the construction industry and the related academic fields. By today, this field has grown such that the organization and definition of the topology of these indicator sets have become necessary. The indicator sets that are used as building sustainability assessment systems can be defined as tools that assess the level of sustainability of a building, as well as classifying and certifying the building based on a series of predefined sustainability parameters or categories. (Díaz López et al., 2019: 7)

The typical structure of indicator sets that are used as building sustainability assessment systems has a three-level hierarchy: the topic, index, and indicator levels. Topics group indexes into diverse areas with the purpose of general guidance. Indexes (or credits/features/imperatives) target different sustainability issues and usually the compliance with index requirements generate points in the rating system. The indexes contain an indicator or a combination of indicators, which are the quantifiable measures of sustainability parameters.

Five main aspects were identified to differentiate between indicator sets: their usage, the targeted scale of assessment, applicability, goals, and evolutionary stage.

Regarding their usage, sustainability indicator sets have been developed by different types of organizations for different purposes. Three main types are identified:

- Research - numerous literatures exist on indicator sets that are not in active use, but mainly exist in theoretical work

- Governmental - metrics that mainly exist of support financial incentive programs for construction projects

- Commercial - third party-developed rating tools that are available on the construction market, the obtainment of a commercial certification provides added market value. 
These three types of indicator sets are not independent from each other. The ones existing in research usually represent the newest indicators that are developed in relation to new ideas and solutions. These then influence the development of commercial and governmental systems. Commercial and governmental systems usually exist in parallel to each other, with some exceptions. For example, the Japanese CASBEE rating tool is adopted as the official local rating tool, but is also used as a commercial international tool as well.

Based on their targeted scale of assessment, building, neighbourhood, and city scale indicator sets are recognized. The general consensus is that, for an effective sustainable strategy, all scales of intervention should be targeted, and their synergies to be utilized. For example, the U.S. Green Building Council (USGBC) has certifications for all three urban scales: LEED v4 Building Design and Construction, LEED v4 for Urban Development, and LEED for Cities.

Based on their applicability, indicator sets can be developed for use by certain countries or in a specific region, but there are also metrics for international usage (that can be limitedly tailored for regional priorities).

Based on their goals, McArthur and Powell (2020) differentiate between sustainability rating systems (those developed to promote environmental sustainability), wellness rating systems (that promote occupant health and wellness), and regenerative design rating systems as the primary motivator for building-scale indicator sets. On city scale, other goals are also present, such as smart- or resilient-city indicator sets.

Chew and Das (2008) identified four generations of building assessment systems:

- First generation: nominal type pass or fail certification system

- Second generation: simple additive systems

- Third generation: weighted additive systems

- Fourth generation: tools which operate based on advanced concepts like building environment efficiency or life cycle impact and cost.

Hundreds of sustainability indicator sets exist today (Lazar \& Chithra, 2020), with similar goals and metrics. This study focuses on the most universally recognized and topically diverse indicator sets. Therefore, from the pool of indicator sets, the following typology was selected:

- International tools - to include the ones with the largest global influence

- Building scale tools - as the building scale systems have been developed the earliest, and have been implemented the longest

- At least second-generation assessment tools - to include the most widely used generation of systems

- Most diverse systems regarding their main principles - to cover the widest range of topics already considered.

Based on the above-listed criterion, five of the most popular and widespread rating tools in the construction industry were selected: LEED, BREEAM, DGNB, WELL, and Living Building Challenge (LBC). 
BREEAM: First published in the U.K. in 1990, BREEAM (Building Research Establishment Environmental Assessment Method) was the world's first sustainability rating scheme for the built environment. It has since been applied in more than 70 countries. The BREEAM New Construction 2016 is selected for this study for assessment, which contains requirements for the building scale in the following topics: Management, Health and Well-being, Energy, Transport, Water, Materials, Waste, Land use and ecology, Pollution and Innovation (BRE, 2016).

LEED: Developed by the USGBC, LEED (Leadership in Energy and Environmental Design) is a voluntary and market-driven rating tool measuring the sustainability of building construction projects. The first version of LEED was developed in 1998 and, since its launch, it has become one of the most internationally widespread sustainability assessment tools. The current version (v4) has been in use since 2014 and contains mandatory and optional requirements in nine topics: Integrative Design, Sustainable sites, Location and Transportation, Water Efficiency, Energy and Atmosphere, Indoor Environmental Quality, Materials and Resources, Innovations, Regional Priorities (USGBC, 2014).

DGNB: The German DGNB (Deutsche Gesellschaft für Nachhaltiges Bauen) system is another variant of the widespread sustainability rating tools, with a life cycle-based approach. The latest international version of the assessment system was published in 2018. This version is applicable to new construction projects with different credit weighting for different functions. In this study, the office function is selected, as it is the most used system version for assessment tools (DGNB, 2018).

WELL: The WELL standard (IWBI, 2018) has been published by the International WELL Building Institute since 2014. The current version is the WELL v2, which has been applicable as a pilot system since 2018. The WELL certification defines requirements for more healthy buildings that improve users' well-being and productivity in 11 topics: Air, Water, Nourishment, Light, Movement, Thermal Comfort, Sound, Materials, Mind, Community, and Innovation. The rating tool includes mandatory and optional requirements that are needed to reach the different certification levels.

$L B C$ : The Living Building Challenge standard was first released in 2006 by the Living Future Institute. Raising the bar above the widespread sustainability rating tools, the main goal of LBC is to eliminate any negative impact a building might have on global health. The standard defines 20 challenges (each with the same weight) in seven topics. In this study, the version 4.0 of LBC is assessed, which was published in 2019 (ILFI, 2019).

\subsection{Methodology}

Studies show that, when evaluating and comparing sustainability assessment tools, only considering their general characteristics does not provide a comprehensive analysis, it is necessary to include the topic, index, and indicator level of the 
different tools (Li, Chen, \& Wang, 2017; Reith \& Orova, 2015). Following this principle, this study attempts to examine the index level of the selected systems in detail.

The following steps are carried out in this study to provide a clear picture of the extent to which regenerative sustainability criteria are incorporated into the selected tool:

1. Determination of regenerative sustainability goals and their thresholds (their required level of performance) based on a literature review. This would provide the basis for assessing how regenerative goals are covered in the selected rating tools.

2. Assessment of each index in the selected tools by the following aspects:

- Related regenerative topic - each credit is connected to a re-generative topic determined in step 1.

- Related aspect of the relevant topic (see Fig. 7.1),

- Type of connection to the topic - Direct: compliance with the requirement of the indicator directly contributes towards a goal defined in the relevant topic of regenerative architecture. Indirect: compliance with the requirement of the indicator does not directly contribute towards its goal, but the implemented solution indirectly affects the relevant goal.

3. Assessment of the level of coverage of regenerative topics:
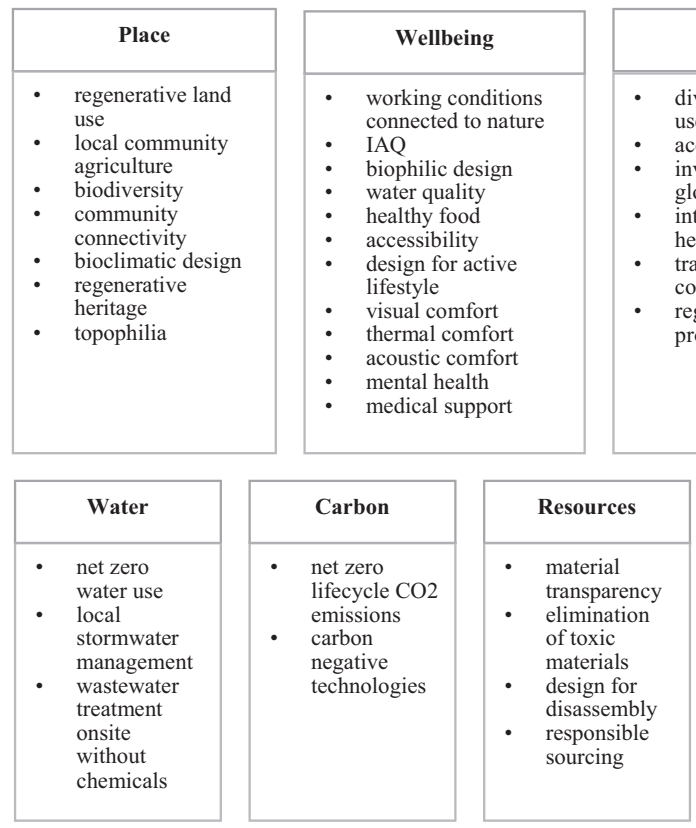
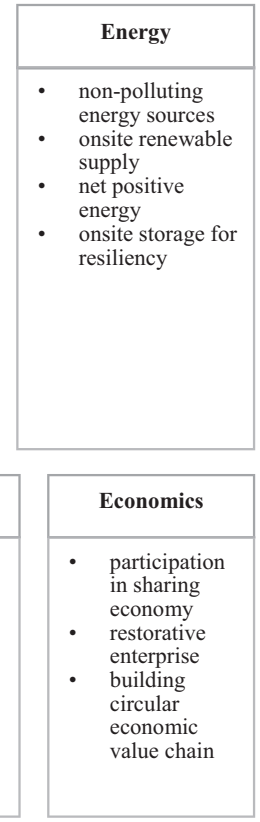

Fig. 7.1 The regenerative goals defined for the nine topics. (Based on Brown et al., 2018) 
- Quantitative assessment: the percentage value of credits covering each regenerative topic is determined, so the relative importance can be determined within each system. This analysis will show which topics are prioritized by the greatest number of rating tools. The results of the quantitative assessment is calculated using the weighted score of the credits in the rating tools. Then the potential scores of credits grouped to each category should be summed. To be able to compare the different assessment tools, the results are shown as ratios of a possible total score.

- Qualitative assessment: the coverage of each regenerative topic is assessed by the following qualities: Topic is not addressed in the rating tool; indirectly addressed; some aspects are addressed; every aspect is addressed, lower benchmarks; every aspect is addressed, same benchmarks.

\subsection{Results}

\subsubsection{Determination of Regenerative Goals}

For the purposes of this study, the fundamental document of the EU funded COSTRESTORE project has been selected as a basis to determine the goals of regenerative sustainability. This study is in line with the definition of regenerative sustainability detailed in the introduction section. COST is a European framework supporting transnational cooperation among researchers, engineers, and scholars across Europe, which funded the RESTORE project that aims to affect a paradigm shift towards restorative sustainability for new and existing buildings across Europe and to promote multidisciplinary knowledge. In the report of Brown et al. (2018), a definition of regenerative architecture is presented organized into nine topics: place, energy, water, well-being, carbon, resources, equity, education, and economics. For each topic, a list of aspects was extracted from the report which is used here to see how the selected rating tools can incorporate them. The following paragraphs detail the nine topics and their regenerative goals, as shown in Fig. 7.1.

The regenerative aspects related to the place topic focus on the integration of the site into the local natural and urban community. The specific goals include the incorporation of design principles (bioclimatic design), regenerative land use options, and community connectivity.

Regenerative energy and water use means net positive water and energy use. The definition of these topics directly referenced from Living Building Challenge (ILFI, 2019), as this standard is leading the way to regenerative energy and water use. Closely connected to these goals is the carbon topic that targets zero carbon emissions, but not just in the use phase but during the whole life cycle of a project. The full list of regenerative aspects related to these topics is shown in Fig. 7.1. 
The well-being topic of regenerative architecture focuses on the comfort and health of building occupants, just as the WELL certification system (IWBI, 2018), which is directly referenced as the most advanced rating tool regarding this topic.

Resources topic defines regenerative resource management with a life cycle approach, which includes responsible sourcing, transparent reporting of built-in materials, the elimination of toxic materials, and the inclusion of options for disassembly during design.

The equity topic targets building users by design and operation goals for inclusivity, accessibility, transparency, and investment in local/global community as well. The education topic also targets building users and wider community with goals of wide participation and inclusion of education programs.

The economics topic focuses on the integration of a project to the circular economic value chain. The linking of sharing economy to the built environment is also considered.

Regarding the benchmarks for the defined regenerative indictors, the current literature indicates some quantifiable goals for some regenerative aspects. In case of energy, water, and carbon use, net positivity serves as regenerative benchmarks. In other cases, there is no clear limit between sustainability and regenerative goals, like in the case of determining the regenerative comfort parameters. And goals where the level of compliance cannot be quantified (e.g. in case of the goal of biophilic design).

Due to the various types of benchmarks, during the assessment, a simplified method was used to evaluate the relation of the strictness of requirements in the different assessment tools to the regenerative benchmarks: 1 - the contribution of the requirement is unquantifiable (e.g. the LEED Integrative Process credit requires to attempt an energy optimization of the project building, which cannot be translated to a quantifiable value); 2 - the credit has lower benchmarks than the regenerative benchmark (e.g. in the LEED assessment tool, the maximum points can be achieved by $50 \%$ improvement in the proposed building performance rating compared with the baseline); 3 - the credit requires the same strictness as regenerative benchmarks (e.g. the LBC assessment requires net positive energy use) or it represents the most stringent values possible (e.g. according to IWBI (2018) WELL requires PM2.5 concentration less than $15 \mu \mathrm{g} / \mathrm{m}$ indoors).

\subsubsection{Results of the Quantitative Assessment}

During the weighting process of each system, different approaches and assumptions were necessary:

- The LEED assessment tool includes mandatory credits that do not receive scoring. Therefore, these were not calculated in comparison, but are mentioned in the assessment separately.

- The BREEAM system also includes prerequisites. For these, the same process was followed. The BREEAM assessment calculates weighting and the inclusion 
of different criteria based on the functionality of the building. For the purposes of the study, a fully fitted office function was considered without special functions like cold storage or laboratory.

- For the WELL assessment, the total score was the sum of all credit scores, and the maximum score per credit category was not considered.

- The LBC tool does not assign scores to its credits, so all credits were taken into account with the same weight.

- For the DGNB system, the credit weighting for offices was taken into account.

The results of the qualitative assessment only calculate with the regenerative topics that are directly incorporated in the indicator system.

Figure 7.2 shows the results of the assessment for the five systems included in this study.

For the LEED rating tool, the mandatory requirements cover the energy, water, well-being, and carbon categories. Regarding the optional credits, $24 \%$ of them incorporate the energy category and similarly high percentages are associated with the coverage of the place (22\%) and the well-being categories (19\%). Also, 20\% of the credits are not directly associated with regenerative goals.

The BREEAM rating tool provides more even coverage of the nine categories in its optional credits. Like in the LEED system, the place, energy, and well-being categories receive the highest coverage, but, unlike LEED, this system incorporates indexes from all categories.

The category coverage assessment of the DGNB system shows that energy is the most important topic in this system as well (21\%), but the resources and economics topics also have high weights in DGNB. Unlike in LEED, here the water topic is the least covered $(2 \%)$.

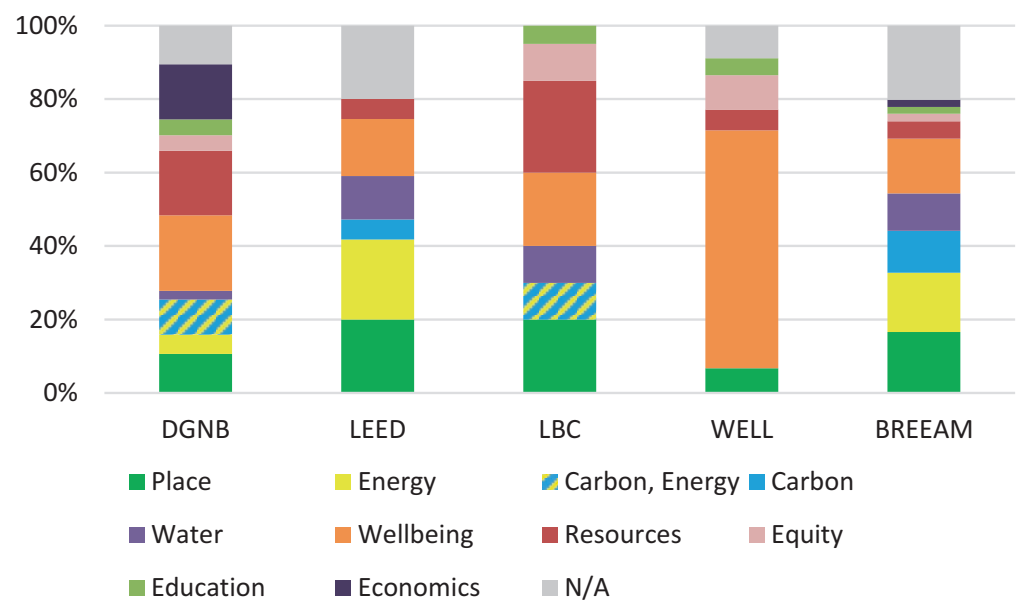

Fig. 7.2 Share of weighted credit values (\%) covering each category 
Table 7.1 Results of the qualitative assessment of the coverage of regenerative goals

\begin{tabular}{|c|c|c|c|c|c|c|c|c|c|}
\hline & Place & Energy & Water & Wellbeing & Carbon & Resources & \begin{tabular}{|l|} 
Equity \\
\end{tabular} & Education & Economics \\
\hline \begin{tabular}{|l} 
BREEAM \\
\end{tabular} & $x$ & $x$ & $x$ & $x$ & $x x$ & $x$ & $x$ & $x$ & $\mathrm{x}$ \\
\hline LEED & $x$ & $x$ & $x$ & $x$ & $x x$ & $x$ & . & - & $\circ$ \\
\hline DGNB & $\mathrm{x}$ & $\mathrm{x}$ & $x$ & $x$ & $x$ & $x x$ & $x$ & $x x$ & \\
\hline WELL & $x$ & $\therefore$ & - & $x x x$ & 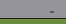 & $\mathrm{x}$ & $x$ & $x x$ & - \\
\hline LBC & $x x x$ & $x x x$ & $x \mathrm{xx}$ & $x$ & $x \mathrm{xx}$ & $x x$ & $x$ & $x x$ & $\circ$ \\
\hline
\end{tabular}

Grey: no aspects are covered; yellow: some aspects are covered, indirectly; light green: some aspects are covered, directly; green: all aspects are covered; dark green: all aspects are covered, regenerative goals

The majority of metrics in the WELL system are related to well-being (65\%), but the four other included categories (place, resources, equity, and education) are incorporated evenly.

The LBC system covers all categories the most evenly. This system has the highest proportion of credits in the resources, place, and well-being topics.

This assessment shows the extent to which these nine topics are incorporated into the selected tools for evaluating regenerative architecture. Table 7.1 includes the results of the assessment. It shows that three of the nine topics are covered at least partially by all these rating tools. The place category is present even in the WELL system, as the regenerative goal of high community connectivity by access to amenities and public transport and the strengthening of local agriculture are goals that also indirectly affect human well-being and health. The well-being and resources topics are also included in every tool, due to the widespread goals of establishing an interior comfort and Indoor Air Quality (IAQ) by installing healthy materials. However, LBC and WELL target more strict levels of comfort and material sourcing and transparency than the more traditional sustainability rating tools, so that they not only limit the negative effects of an artificial environment but also attempt to implement positive effects, such as improved health and productivity.

The table also shows that regenerative economics goals are the least covered in the different systems. DGNB provides the best results, as the rating tool is aligned with circular economy principles. The other systems mainly reference regenerative economic goals, with including indicators requiring the participation in sharing economy (e.g. sharing community spaces with local community or shared transport facilities).

Regarding the depth of alignment with regenerative goals, LBC targets positive impacts for all regenerative goals in four topics (place, energy, water, and carbon). In two other categories - resources and education - LBC covers all topics, but the requirement could be more ambitious (e.g. the participatory project development is only partially included in the rating tool). Table 7.2 also shows that, in the Wellbeing and Equity categories, some of the goals are not addressed in the system, and the least covered is the Economics category.

Regarding the other rating tools, WELL incorporates all the regenerative wellbeing goals and partially covers only four other topics. DGNB and BREEAM incorporate all the categories, but, in most cases, not all aspects and with less ambitious 
Table 7.2 Results of the $\mathrm{LBC}$ assessment about covering regenerative goals

\begin{tabular}{|c|c|c|c|c|c|c|c|c|}
\hline Place & $\begin{array}{l}\text { regenerative } \\
\text { land use }\end{array}$ & $\begin{array}{l}\text { local } \\
\text { community } \\
\text { agriculture }\end{array}$ & biodiversity & $\begin{array}{l}\text { community } \\
\text { connectivity }\end{array}$ & $\begin{array}{l}\text { bioclimatic } \\
\text { design }\end{array}$ & $\begin{array}{l}\text { regenerative } \\
\text { heritage }\end{array}$ & topophilia & \multirow[t]{2}{*}{$\mathrm{xxx}$} \\
\hline Covered & 3 & 3 & 3 & 3 & 3 & 3 & 3 & \\
\hline Energy & \begin{tabular}{|l} 
non \\
polluting \\
energy \\
sources \\
\end{tabular} & $\begin{array}{l}\text { onsite } \\
\text { renewable } \\
\text { supply }\end{array}$ & $\begin{array}{l}\text { net positive } \\
\text { energy }\end{array}$ & $\begin{array}{l}\text { onsite storage } \\
\text { for resiliency }\end{array}$ & & & & \multirow[t]{2}{*}{$\mathrm{xxx}$} \\
\hline Covered & 3 & 3 & 3 & 3 & & & & \\
\hline Water & $\begin{array}{l}\text { net zero } \\
\text { water use }\end{array}$ & $\begin{array}{l}\text { local } \\
\text { stormwater } \\
\text { management }\end{array}$ & $\begin{array}{l}\text { wastewater } \\
\text { treatment } \\
\text { onsite without } \\
\text { chemicals }\end{array}$ & & & & & \multirow[t]{2}{*}{$\mathrm{xxx}$} \\
\hline Covered & 3 & 3 & 3 & & & & & \\
\hline Wellbeing & \begin{tabular}{|l|} 
working \\
conditions \\
connected to \\
nature
\end{tabular} & IAQ & $\begin{array}{l}\text { biophilic } \\
\text { design }\end{array}$ & water quality & $\begin{array}{l}\text { healthy food } \\
\text { accessibility }\end{array}$ & $\begin{array}{l}\text { design for } \\
\text { active } \\
\text { lifestyle }\end{array}$ & $\begin{array}{l}\text { visual } \\
\text { comfort }\end{array}$ & $\mathrm{x}$ \\
\hline \multirow[t]{3}{*}{ Covered } & 3 & 3 & 3 & 0 & 0 & 0 & 0 & \\
\hline & $\begin{array}{l}\text { thermal } \\
\text { comfort }\end{array}$ & $\begin{array}{l}\text { acoustic } \\
\text { comfort }\end{array}$ & mental health & $\begin{array}{l}\text { medical } \\
\text { support }\end{array}$ & & & & \multirow[t]{2}{*}{$\mathrm{x}$} \\
\hline & 2 & 0 & 0 & 0 & & & & \\
\hline Carbon & \begin{tabular}{|l|} 
net zero \\
lifecycle \\
$\mathrm{CO} 2$ \\
emissions \\
\end{tabular} & $\begin{array}{l}\text { carbon } \\
\text { negative } \\
\text { technologies }\end{array}$ & & & & & & \multirow[t]{2}{*}{$\mathrm{xxx}$} \\
\hline Covered & 3 & 3 & & & & & & \\
\hline Resources & $\begin{array}{l}\text { material } \\
\text { transparency }\end{array}$ & $\begin{array}{l}\text { elimination } \\
\text { of toxic } \\
\text { materials } \\
\end{array}$ & $\begin{array}{l}\text { design for } \\
\text { disassembly }\end{array}$ & $\begin{array}{l}\text { responsible } \\
\text { sourcing }\end{array}$ & & & & \multirow[t]{2}{*}{$\mathrm{xx}$} \\
\hline Covered & 3 & 3 & 2 & 3 & & & & \\
\hline Equity & $\begin{array}{l}\text { diverse, } \\
\text { inclusive } \\
\text { users }\end{array}$ & accessibility & $\begin{array}{l}\text { investment in } \\
\text { local / global } \\
\text { community } \\
\text { (charities) }\end{array}$ & $\begin{array}{l}\text { integration of } \\
\text { cultural } \\
\text { heritage }\end{array}$ & $\begin{array}{l}\text { transparency } \\
\text { of company } \\
\text { procedures }\end{array}$ & $\begin{array}{l}\text { regenerative } \\
\text { CSR } \\
\text { programs }\end{array}$ & & \multirow[t]{2}{*}{$\mathbf{x}$} \\
\hline Covered & 3 & 3 & 3 & 0 & 3 & 0 & & \\
\hline Education & \begin{tabular}{|l|}
$\begin{array}{l}\text { participatory } \\
\text { processes }\end{array}$ \\
\end{tabular} & $\begin{array}{l}\text { inspiration / } \\
\text { education }\end{array}$ & & & & & & \multirow[t]{2}{*}{$\mathrm{xx}$} \\
\hline Covered & 2 & 3 & & & & & & \\
\hline Economics & $\begin{array}{l}\text { participation } \\
\text { in sharing } \\
\text { economy }\end{array}$ & $\begin{array}{l}\text { restorative } \\
\text { enterprise }\end{array}$ & $\begin{array}{l}\text { building } \\
\text { circular } \\
\text { economic } \\
\text { value chain } \\
\end{array}$ & & & & & \multirow[t]{2}{*}{ o } \\
\hline Covered & 1 & 0 & 1 & & & & & \\
\hline
\end{tabular}

0 - Not covered; 1 - Indirectly covered; 2 - Covered; 3 - Covered, same goals

goals. LEED does not cover the equity and education topics at all, nor does it set ambitious goals in the other categories.

\subsection{Discussion}

The results of the quantitative and qualitative assessments showed that, on average, the well-being-related aspects of regenerative architecture are included with the highest weight in the five assessment tools. It also shows that the education-, economic-, and carbon-related issues are underrepresented. It should be noted that the 
carbon category coverage is indirectly improved, as the energy and some of the resources related requirements contribute toward net positive carbon goals.

The analysis of the five selected rating tools suggests that the typology of the tools, based on their purpose (sustainability, wellness, and regenerative systems), is the defining factor about how they incorporate regenerative goals. As expected, since it was developed specifically to address regenerative sustainability, LBC is much more comprehensive in its incorporation of the identified aspects, addressing the majority of issues highlighted in the academic literature. Meanwhile, on the other end of the scale, WELL focuses on the narrowest goal, as in providing healthy buildings for occupants, but by doing it through the incorporation of the widest range of health-related regenerative aspects as possible. In the middle stand the mainly sustainability-oriented rating tools (LEED, BREEAM, DGNB) that provide a good coverage to the regenerative goals that originated from traditional sustainability goals, but with limited thresholds and limited coverage of education and equity topics. From among the three sustainability-focused systems, LEED performs the worst, as it does not cover the equity and education topics at all, nor does it set ambitious goals in the other categories.

\subsection{Conclusions}

To provide a basis for the assessment rating tools, this research conducted a literature review of regenerative architecture. The definition of the topics and goals of regenerative sustainability showed that while the concept is well defined, its application supported by performance metrics needs further refinement. Several of the defined regenerative goals do not have clear performance thresholds that can hinder their inclusion into market-accepted assessment tools.

The previous chapters show evidence that while in most cases the assessed credits of the five rating systems are not primarily developed to promote regenerative architecture, they incorporate a significant portion of regenerative goals, especially goals targeting well-being-related issues and goals about the deeper connection to natural and built environment. The extent to which this is true varies significantly between the rating tools. However, a significant gap exists about the incorporation of 'soft' topics, such as education and equity. This may be because these goals have less direct and quantifiable evidence on improving the environmental dimension of sustainability, therefore these were left out from the sustainability-focused rating tools.

Despite the conclusive evidence in literature that the main factor in the decisionmaking processes of construction projects is cost- and return of investment-based, the studied rating tools incorporate the least amount of economics-related aspects of regenerative sustainability.

The previous paragraphs summarized the main identified gaps in this study. Based on these, the main areas for improvement are evident: improve the performance threshold of sustainability assessment systems to close the gap towards 
regenerative goals; improve the in-depth coverage of economics topics; and include soft regenerative aspects into sustainability assessments. It is recognized that the update of these systems is a complex task and a balance is targeted between leadership in sustainability performance and market readiness, but it is also necessary to constantly challenge these rating tools when new ideas emerge.

Regenerative sustainability principles not only intended to affect the building scale but its goals can be more easily translated when the different scales of the urban fabric are considered together. Therefore, as a next step for this research topic, the existing neighbourhood- and city-scale rating tools should be included in a similar assessment.

\section{References}

Akturk, A. (2016). Regenerative design and development for a sustainable future: Definitions and tool evaluation. Minneapolis, MN: University of Minnesota.

Attia, S. (2016). Towards regenerative and positive impact architecture: A comparison of two net zero energy buildings. Sustainable Cities and Society, 26, 393-406. https://doi.org/10.1016/j. scs.2016.04.017. Elsevier B.V.

Bayulken, B., \& Huisingh, D. (2015). A literature review of historical trends and emerging theoretical approaches for developing sustainable cities (part 1). Journal of Cleaner Production, 109(Part 1), 11-24. https://doi.org/10.1016/j.jclepro.2014.12.100. Elsevier Ltd.

BRE Global Ltd. (2016). BREEAM international new construction 2016 technical manual, p. 454.

Brown, M., et al. (2018). Sustainability, restorative to regenerative an exploration in progressing a paradigm shift in built environment thinking, from sustainability to restorative sustainability and on to regenerative sustainability. COST action CA16114 RESTORE: REthinking sustainability TOwards a regenerative economy, Working Group One Report: Restorative Sustainability.

Chew, M. Y. L., \& Das, S. (2008). Building grading systems: A review of the state-of-the-art. Architectural Science Review, 51(1), 3-13. https://doi.org/10.3763/asre.2008.5102.

DGNB Global Benchmark for SustainabilitySustainability. (2018). DGNB system criteria set new construction building. https://doi.org/10.3390/life4040745.

Díaz López, C., et al. (2019). A comparative analysis of sustainable building assessment methods. Sustainable Cities and Society, 49(April), 101611. https://doi.org/10.1016/j.scs.2019.101611. Elsevier.

Du Plessis, C., \& Brandon, P. (2015). An ecological worldview as basis for a regenerative sustainability paradigm for the built environment. Journal of Cleaner Production, 109, 53-61. https:// doi.org/10.1016/j.jclepro.2014.09.098. Elsevier Ltd.

EURESTORE. (2020). https://www.eurestore.eu/working-groups/wg4-rethinking-technology/

Haapio, A., \& Viitaniemi, P. (2008). A critical review of building environmental assessment tools. Environmental Impact Assessment Review, 28(7), 469-482. https://doi.org/10.1016/j. eiar.2008.01.002

Hes, D., \& Du Plessis, C. (2015). Designing for hope: Pathways to regenerative sustainability (p. 252). Abingdon, UK/New York: Routledge. ISBN:978-1-138-80061-8. ISBN: 978-1-138-80062-5. ISBN:978-1-315-75537-3.

ILFI International Living Future Institute. (2019). Living building challenge 4.0. https://doi. org/10.1145/3128128.3128156.

Illankoon, I. M. C. S., et al. (2017). Key credit criteria among international green building rating tools. Journal of Cleaner Production, 164, 209-220. https://doi.org/10.1016/j. jclepro.2017.06.206. Elsevier Ltd. 
IWBI International WELLWELL Building Institute. (2018). WELL v2 the next version of the WELL building standard.

Jiang, B. et al. (2020) Incorporating biophilic criteria into green building rating tools: Case study of Green Mark and LEED, Environmental Impact Assessment Review. 82(February), p. 106380. doi: https://doi.org/10.1016/j.eiar.2020.106380. Elsevier

Lazar, N., \& Chithra, K. (2020). A comprehensive literature review on development of building sustainability assessment systems. Journal of Building Engineering, 32(April), 101450. https:// doi.org/10.1016/j.jobe.2020.101450. Elsevier Ltd.

Li, Y., Chen, X., \& Wang, X. (2017). A review of studies on green building assessment methods by comparative analysis. Energy \& Buildings. https://doi.org/10.1016/j.enbuild.2017.04.076. Elsevier B.V.

McArthur, J. J., \& Powell, C. (2020). Health and wellness in commercial buildings: Systematic review of sustainable building rating systems and alignment with contemporary research. Building and Environment, 171, 106635. https://doi.org/10.1016/j.buildenv.2019.106635. Elsevier Ltd.

Naboni, E., et al. (2019). A digital workflow to quantify regenerative urban design in the context of a changing climate. Renewable and Sustainable Energy Reviews, 113(February), 109255. https://doi.org/10.1016/j.rser.2019.109255. Elsevier Ltd.

Reith, A., \& Orova, M. (2015). Do green neighbourhood ratings cover sustainability? Ecological Indicators, 48, 660-672. https://doi.org/10.1016/j.ecolind.2014.09.005. Elsevier Ltd.

Sonetti, G., Brown, M., \& Naboni, E. (2019). About the triggering of UN sustainable development goals and regenerative sustainability in higher education. Sustainability, 11(1), 1-17. https:// doi.org/10.3390/su11010254. Switzerland.

Svec, P., Berkebile, R., \& Todd, J. A. (2012). REGEN: Toward a tool for regenerative thinking. Building Research and Information, 40(1), 81-94. https://doi.org/10.1080/0961321 8.2012.629112

United Nations. (1987). Report of the world commission on Environment and development: Our common future. https://doi.org/10.9774/gleaf.978-1-907643-44-6_12.

USGBC U.S. Green Building Council. (2014). LEED 44 reference guide for building design and construction.

Open Access This chapter is licensed under the terms of the Creative Commons Attribution 4.0 International License (http://creativecommons.org/licenses/by/4.0/), which permits use, sharing, adaptation, distribution and reproduction in any medium or format, as long as you give appropriate credit to the original author(s) and the source, provide a link to the Creative Commons license and indicate if changes were made.

The images or other third party material in this chapter are included in the chapter's Creative Commons license, unless indicated otherwise in a credit line to the material. If material is not included in the chapter's Creative Commons license and your intended use is not permitted by statutory regulation or exceeds the permitted use, you will need to obtain permission directly from the copyright holder.

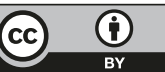

